\title{
Impact of office tenants' electricity use on the cost-optimal solutions in a cold climate
}

\author{
Helena Kuivjõgi ${ }^{1 *}$, Liina Laas $^{1}$, Andrea Ferrantelli ${ }^{1}$ and Martin Thalfeldt ${ }^{2,1}$ \\ ${ }^{1}$ nZEB Research Group, Tallinn University of Technology, Ehitajate tee 5, 19086 Tallinn, Estonia \\ ${ }^{2}$ Smart City Center of Excellence, Tallinn University of Technology, Ehitajate tee 5, 19086 Tallinn, Estonia
}

\begin{abstract}
The buildings' energy performance requirements in Estonia are based on cost-optimality analysis according to the EPBD and pre-defined building performance simulation (BPS) input data from EN 167981:2019. Previous studies have shown that the real electricity use of office building tenants differs from the currently used input data in BPS in Estonia - less in total energy use, but more in the shape of the profiles. The aim of this work is to investigate what is the impact of these differences on the cost-optimal solutions, which are identified based on BPS and the self-consumption of the photovoltaic panel (PV) systems. This study describes the energy performance and construction cost analysis of a new office building in Tallinn, Estonia. BPS based on the EN 16798-1 and a model derived from measurements in a real building were conducted and cost-optimal building solutions identified. The variables were building envelope insulation thickness, air handling unit size and effectiveness, electrical lighting control principles and PV system nominal power. The calculated energy use of the building with the two different sets of input data differed significantly. However, the set of cost-optimal solutions identified with EN 16798-1:2019 input data had minor differences from the set of solutions identified with the more realistic model. The decrease of net present value over 20-year period for cost-optimal solution was $11-14 € / \mathrm{m}^{2}$ compared to the designed building. The realistic office tenants' electricity model increased the calculated self-consumption of the PV system from $95 \%$ to $100 \%$.
\end{abstract}

\section{Introduction}

Building energy calculation have to correspond to the minimum requirements [1], [2] in Estonia. New buildings have to achieve NZEB level that has energy performance certificate $(\mathrm{EPC})$ rate $100 \mathrm{kWh} / \mathrm{m}^{2} \mathrm{y}$. Furthermore, these requirements as well European Parliament directives [3], [4] sets, that simultaneously achieving the energy efficiency in a building, there is a need to focus on cost-optimality. Energy efficiency should not be achieved if the cost-optimality suffers. Therefore, the energy efficiency should be calculated accurately, so the building solutions will be cost-optimal in practice. However, some studies [5], [6] shows that real electricity use in office buildings differs from the electricity use calculated by currently used input data in BPS.

Renewable energy produced in the building is included in EPC calculation, but for photovoltaics (PV), only the PV generation used in the building (selfconsumption) will be involved. Estonian minimum requirements set the PV self-consumption for an office buildings $90 \%$. J. Ivanov found out in his thesis, that the self-consumption (calculated with requirements input data) is $75-86 \%$ in one cost-optimal office building. The present study investigates, how much the real electricity consumption will effect the PV system self- consumption compared to regulation-based calculations.

This study investigates the impact of tenant electricity use that depends on the shape of the profiles used in BPS. BPS based on the EN 16798-1 and a model derived from measurements in the real building were conducted. Derived model has been done by Hans K. Aljas et al. study [7], where they analyzed four buildings tenant electricity use. The building used in this study has the highest electricity consumption compared to other buildings in study [7], to see the extreme case. Costoptimal building solutions were identified and compared in between two profiles.

\section{Methods and model}

\subsection{Building description}

The reference object was one designed commercial building (bld.) what is under construction right now and planned to be ready at the beginning of 2022. This study focuses on the office area of this bld., what is from the fifth to thirteenth floor (Table 1). Total heat loss of the bld. envelope per heated floor area was $0.45 \mathrm{~W} /\left(\mathrm{m}^{2} \times \mathrm{K}\right)$ and the envelope insulation was mineral wool. The building heating and cooling source was a geothermal heat pump and the thermally activated building system

\footnotetext{
*Corresponding author : helena.kuivjogi@taltech.ee
} 
(TABS) will regulate the indoor temperature with waterbased ceiling panels. The photovoltaic (PV) panels of nominal power of $5 \mathrm{~kW}\left(1.3 \mathrm{~W} / \mathrm{m}^{2}\right)$ will be installed on the roof. The building will has passive shading (ribs) facing to the south, and in other directions windows with effective solar factor.

Table 1. Reference office building envelope and system parameters

\begin{tabular}{|c|c|}
\hline Heated floor area, $\mathrm{m}^{2}$ & 3833 \\
\hline External wall (EW) insulation thickness, mm & $200+60$ \\
\hline EW thermal conductivity, $\mathrm{W} /\left(\mathrm{m}^{2} \times \mathrm{K}\right)$ & 0.15 \\
\hline External roof (ER) insulation thickness, mm & $270+30$ \\
\hline ER thermal conductivity, $\mathrm{W} /\left(\mathrm{m}^{2} \times \mathrm{K}\right)$ & 0.1 \\
\hline WWR, \% & 61 \\
\hline Windows solar factor in south, - & 0.54 \\
\hline Windows solar factor in other directions, - & 0.22 \\
\hline Lighting control & on/off \\
\hline
\end{tabular}

\subsection{Two energy simulation models}

Two energy simulation models were composed on the basis of the reference building. The first model (ENprofile) was based on the usage profile from standard EN16798-1:2019 (green line in Figure 1), and the second model (M-profile) was derived from measurements in a real building with the usage profile described in Section 2.3.

The calculation models were simulated with IDA ICE 4.8. There was used an Estonian test reference year made over a period of 31 years, from 1970 to 2000 . That contains typical months from a number of different years. [8]

The bld. model starts from the fifth floor and has 4 floors up. The third ( $7^{\text {th }}$ in full bld. context) floor output has been multiplied with six as it is similar to the five following floors. The floors are divided into four zones facing to different directions and one zone is for the corridor. All parameters included in the simulation calculation have been taken from regulation [2], which are shown in Table 2. Only lighting usage has been taken as the project designed value of LED lamps (regulation states only $10 \mathrm{~W} / \mathrm{m}^{2}$ as for florescence lamps). The self-consumption of the photovoltaic panel has been calculated also by IDA ICE simulation.

\subsection{Development of measurement-based model}

The appliances and lighting electricity use profile has been composed based on the model from Hans K. Aljas et al. study [7]. The model used in this study was based on one existing office bld. in Tallinn, that has higher electricity use than usual as there are more IT offices. The lighting and appliances electricity use per hour has been calculated by the equations used in study [7] for every day over one year and then divided by power of the summary of default appliances and lighting power (Table 2) and then got the usage ratio profile (upper orange line in Figure 1). For the simulations in
IDA-ICE, there has been used a macro to determine the usage profile. In the macro, there has been used the usage ratio profile together with the same equations and the program code calculated the final energy use by multiplying the profile with the same default appliances and lighting power from Table 2.

Table 2. The parameters in energy simulation models

\begin{tabular}{|c|c|}
\hline Occupancy, W/m² & 5 \\
\hline Appliances, $\mathrm{W} / \mathrm{m}^{2}$ & 12 \\
\hline Lighting, W/m² & 6.37 \\
\hline Usage in workdays, $\mathrm{h}$ & $\begin{array}{l}7: 00- \\
18: 00 \\
\end{array}$ \\
\hline Usage in weekends and holidays, $\mathrm{h}$ & 0 \\
\hline Usage ratio, - & 0.55 \\
\hline Heating set-point, ${ }^{\circ} \mathrm{C}$ & 21 \\
\hline Cooling set-point, ${ }^{\circ} \mathrm{C}$ & 25 \\
\hline Illuminance, $1 \mathrm{x}$ & 500 \\
\hline Air change rate, $1 /\left(\mathrm{s} \times \mathrm{m}^{2}\right)$ & 2 \\
\hline Heat system efficiency factor, - & 0.99 \\
\hline Geothermal heat pump SCOP, - & 4.4 \\
\hline Geothermal heat pump COP for DHW, - & 2.7 \\
\hline Geothermal heat pump SEER, - & 6.1 \\
\hline Drycooler SEER, - & 3.5 \\
\hline AHU SFP kW/ $\left(\mathrm{m}^{3} / \mathrm{s}\right)$ & 1.72 \\
\hline AHU heat recovery efficiency $\eta, \%$ & 78 \\
\hline DHW specific use, $1 /\left(\mathrm{m}^{2} \times y\right)$ & 103 \\
\hline
\end{tabular}

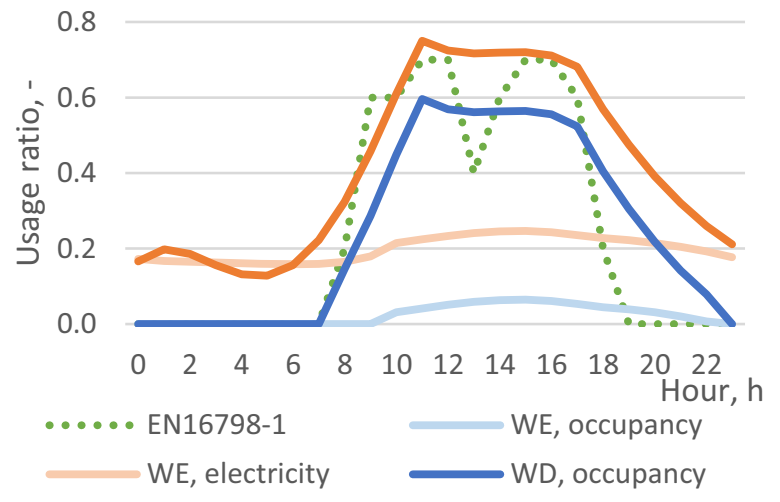

Figure 1. The usage ratio of lighting, appliances electricity use and occupancy for weekdays (WD) and weekends\&holidays (WE)

The usage profile for occupancy, as the lower line in Figure 1, has been derived from the appliances and lighting profile. The constant background electricity use $\left(3.4 \mathrm{~W} / \mathrm{m}^{2}\right.$ as usage ratio 0.19$)$ has been subtracted and non-working hours has been excluded.

The difference of EN- and M-profile is considerable. EN-profile is limited to working hours (719:00 and no work in weekends), but from M-profile in Figure 1 one can see that occupants will work also outside so-called working hours. Appliances and lighting power is active even until 23:00 and it is assumed that occupants will be present at this time. Furthermore, there is occupancy at weekends. 


\subsection{The selection of cost-optimal solutions}

Inside the reference models, the variables in Table 3 have been changed to estimate the energy efficiency of measures. Altogether, 20 models have been composed for each profile to calculate the energy use with the simulation program. Furthermore, the energy performance certificate, here named as the primary energy (PE) use, has been calculated for each measure using primary side factors from Table 2. The added investment in relation to the previous measure has been used to estimate the cost-optimality of every measure and model.

\subsection{The final combinations of cost-optimal solutions}

The combinations of cost-optimal solutions shown in Table 4 were selected among the measures in Table 3. For comparison, the project-designed combination has been calculated. The base model was combined with the worst measures that gave the highest PE. That was the base level for energy efficiency estimation and the zero level of investment cost. Further combinations were composed by adding cost-optimal measures to the base model considering the additional investment per 1 kWh saved primary energy $(€ / \mathrm{kWh})$ of the measures that was compared to the previous change. The first measure had the smallest investment per saved energy and so forth. The previous measure was retained for each next measure. Finally, the four characteristic combinations have been selected in addition to the designed and base model. Subsequently, the PE use has been estimated by arithmetical calculation as well with the simulation program. Cost-optimality of these combinations has been calculated with the net present value over 20-year, the energy price was $91.7 € / \mathrm{MWh}$, nominal interest rate was $2.7 \%$, and inflation rate $1.7 \%$.
Table 3. Changed variables and measures with additional investment compared to the base model

\begin{tabular}{|c|c|c|c|}
\hline Measures & $\begin{array}{l}\text { Changed } \\
\text { variable }\end{array}$ & $\begin{array}{c}\text { Variable } \\
\text { value }\end{array}$ & $\begin{array}{c}\text { Added } \\
\text { investment, } \\
€ / \mathrm{m}^{2} \\
\end{array}$ \\
\hline EW100 & \multirow{5}{*}{$\begin{array}{c}\mathrm{EW} \\
\text { insulation, } \\
\mathrm{mm}\end{array}$} & 100 & 0 \\
\hline EW150 & & 150 & 8 \\
\hline EW200 & & 200 & 7 \\
\hline EW250 & & 250 & 6 \\
\hline EW300 & & 300 & 5 \\
\hline ER180 & \multirow{5}{*}{$\begin{array}{c}\text { ER } \\
\text { insulation, } \\
\mathrm{mm}\end{array}$} & 180 & 0 \\
\hline ER210 & & 210 & 3 \\
\hline ER240 & & 240 & 4 \\
\hline ER270 & & 270 & 8 \\
\hline ER300 & & 300 & 4 \\
\hline Vent_1 & \multirow{3}{*}{$\begin{array}{c}\mathrm{AHU} \\
\text { parameters, } \\
\% \\
\mathrm{~kW} /\left(\mathrm{m}^{3} / \mathrm{s}\right)\end{array}$} & $\begin{array}{cc}y= & 77.3 \\
\mathrm{SFP}= & 2.33\end{array}$ & $0 €$ \\
\hline Vent_2 & & $\begin{array}{ll}\mathrm{y}= & 78.0 \\
\mathrm{SFP} & 1.72\end{array}$ & $1000 €$ \\
\hline Vent_3 & & $\begin{array}{ll}y= & 78.8 \\
\mathrm{SFP}= & 1.52 \\
\end{array}$ & $1000 €$ \\
\hline LED & \multirow{3}{*}{$\begin{array}{l}\text { Lighting } \\
\text { control }\end{array}$} & on/off & 0 \\
\hline LED_Sen & & Sensors & 8 \\
\hline $\begin{array}{c}\text { LED } \\
\text { Sen\&dim }\end{array}$ & & $\begin{array}{l}\text { Sensors with } \\
\text { dimming }\end{array}$ & 6 \\
\hline $\mathrm{PV} 0 \mathrm{~W} / \mathrm{m}^{2}$ & \multirow{4}{*}{$\begin{array}{l}\text { PV power, } \\
\text { kW }\end{array}$} & 0 & $0 €$ \\
\hline $\begin{array}{l}\mathrm{PV} 1.3 \\
\mathrm{~W} / \mathrm{m}^{2}\end{array}$ & & 5 & $5000 €$ \\
\hline $\begin{array}{l}\mathrm{PV} 3.7 \\
\mathrm{~W} / \mathrm{m}^{2} \\
\end{array}$ & & 14 & $14000 €$ \\
\hline $\begin{array}{l}\text { PV } 6.0 \\
\text { W/m }\end{array}$ & & 23 & $24000 €$ \\
\hline
\end{tabular}

Table 4. Combinations of cost-optimal solutions for EN- and M-profile (the only difference is highlighted)

\begin{tabular}{|l|c|l|l|c|c|}
\hline \multicolumn{1}{|c|}{ Combinations } & $\begin{array}{c}\text { EW/ER } \\
\text { insulation, mm }\end{array}$ & AHU parameters & \multicolumn{1}{|c|}{ Lighting control } & $\begin{array}{c}\text { PV power, } \\
\mathbf{W} / \mathbf{m}^{\mathbf{2}}\end{array}$ & $\begin{array}{c}\mathbf{P E}, \\
\mathbf{k W h} / \mathbf{m}^{\mathbf{2}} \mathbf{y}\end{array}$ \\
\hline As designed_EN & $200 / 270$ & $\mathrm{y}=78,0 \mathrm{SFP}=1,72$ & on/off & 1.3 & 104.3 \\
\hline 1K BModel EN & $100 / 180$ & $\mathrm{y}=77,3 \mathrm{SFP}=2,33$ & on/off & 0 & 116.2 \\
\hline 2K EN & $100 / 180$ & $\mathrm{y}=78,8 \mathrm{SFP}=1,52$ & on/off & 6.0 & 95.2 \\
\hline 3K EN & $100 / 180$ & $\mathrm{y}=78,8 \mathrm{SFP}=1,52$ & Sensors & 6.0 & 84.8 \\
\hline 4K EN & $100 / 180$ & $\mathrm{y}=78,8 \mathrm{SFP}=1,52$ & Sensors with dimming & 6.0 & 83.2 \\
\hline 5k EN & $150 / 210$ & $\mathrm{y}=78,8 \mathrm{SFP}=1,52$ & Sensors with dimming & 6.0 & 82.6 \\
\hline As designed_M & $200 / 270$ & $\mathrm{y}=78,0 \mathrm{SFP}=1,72$ & on/off & 1.3 & 155.8 \\
\hline 1K_BModel_M & $100 / 180$ & $\mathrm{y}=77,3 \mathrm{SFP}=2,33$ & on/off & 0 & 164.2 \\
\hline 2K M & $100 / 180$ & $\mathrm{y}=78,8 \mathrm{SFP}=1,52$ & Sensors & 6.0 & 137.8 \\
\hline 3K M & $100 / 180$ & $\mathrm{y}=78,8 \mathrm{SFP}=1,52$ & Sensors & 126.6 \\
\hline 4K_M & $100 / 180$ & $\mathrm{y}=78,8 \mathrm{SFP}=1,52$ & Sensors with dimming & 6.0 & 124.1 \\
\hline 5K_M & $150 / 210$ & $\mathrm{y}=78,8 \mathrm{SFP}=1,52$ & Sensors with dimming & 6.0 & 123.6 \\
\hline
\end{tabular}




\section{Results}

\subsection{Primary energy use is significantly different}

Designed building PE use with EN-profile was $104.3 \mathrm{kWh} / \mathrm{m}^{2} \times \mathrm{y}$ and was a little out of the boundaries that requirement set $\left(100 \mathrm{kWh} / \mathrm{m}^{2} \times \mathrm{y}\right.$ is the NZEB level for new blds.). The simulation done with M-profile resulted with PE use $152.4 \mathrm{kWh} / \mathrm{m}^{2} \times \mathrm{y}$. The M-profile increased the PE use about $37-52 \mathrm{kWh} / \mathrm{m}^{2} \mathrm{y}$ for measures, compared to EN-profile. Extended data about $\mathrm{PE}$ use of all measures are in Figure 11 and Figure 12 in Appendix 1.

The smallest influence on PE had the measure of changing the insulation thickness (Figure 3). The average difference of PE was only in 0.35 and 0.51 $\mathrm{kWh} / \mathrm{m}^{2} \mathrm{y}$ (respectively, for M-profile and EN-profile). Figure 4 shows that the lighting control measure had the biggest influence on PE difference and has substantial difference in between profiles. The best PE difference and extra cost combination was for AHU size measure (Figure 6) as the PE difference was similar to the lighting control measure, but the extra cost was more than 25 times smaller.

Photovoltaic panel self-consumption was $100 \%$ for M-profile and about $86-98 \%$ for EN-profile with heat pump, as shown in Figure 2. Depending on PV system installed power, the primary energy use was reduced about 2.4-11.2 $\mathrm{kWh} / \mathrm{m}^{2} \mathrm{y}$, and 2.4-9.6 $\mathrm{kWh} / \mathrm{m}^{2} \mathrm{y}$ respectively, for M-profile and EN-profile, as shown in Figure 5.

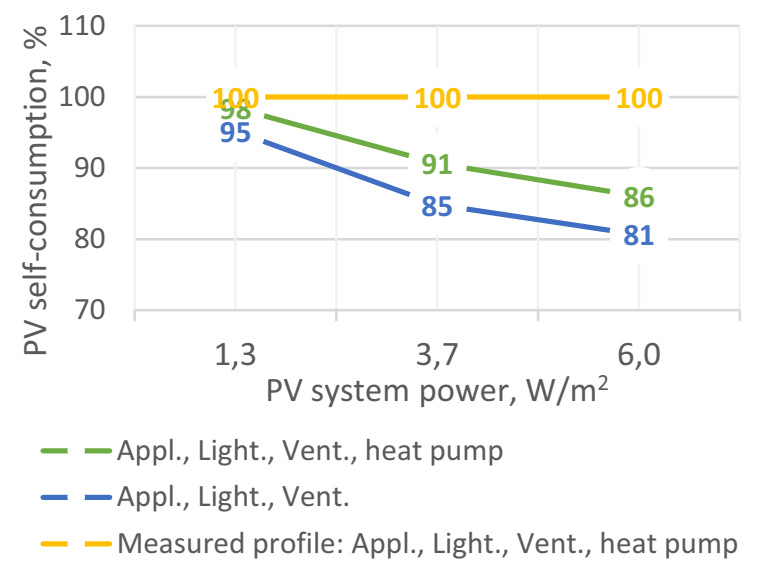

Figure 2. Photovoltaics self-consumption for M-profile and EN-profile

The net energy use of the combinations defined in Table 4 will vary significantly in between two profiles, as shown in Figure 7. For the calculation with Mprofile, the energy use for lighting and appliances increased 90-180\% compared to EN-profile calculation. Due to higher heat gain from appliances, lighting and occupancy, the heating net energy use decreased about $30-35 \%$, and cooling net energy use increased for 50$66 \%$ to ensure the normal temperature and comfort.

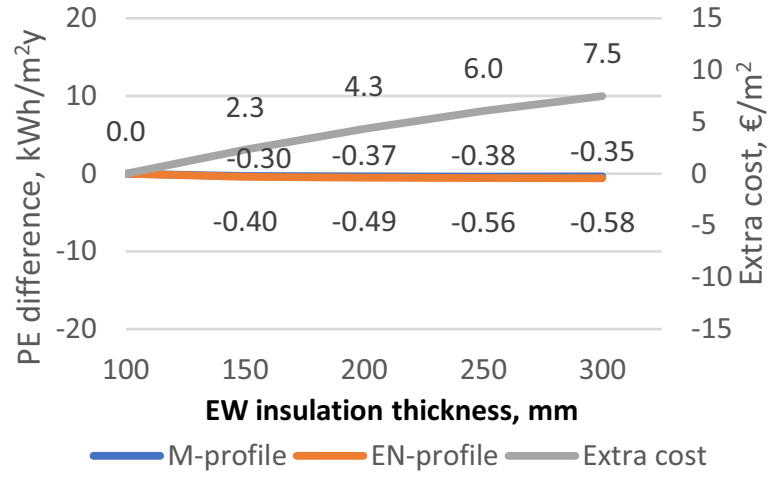

Figure 3. EW insulation measure primary energy (PE) change and extra investment cost compared to the base model

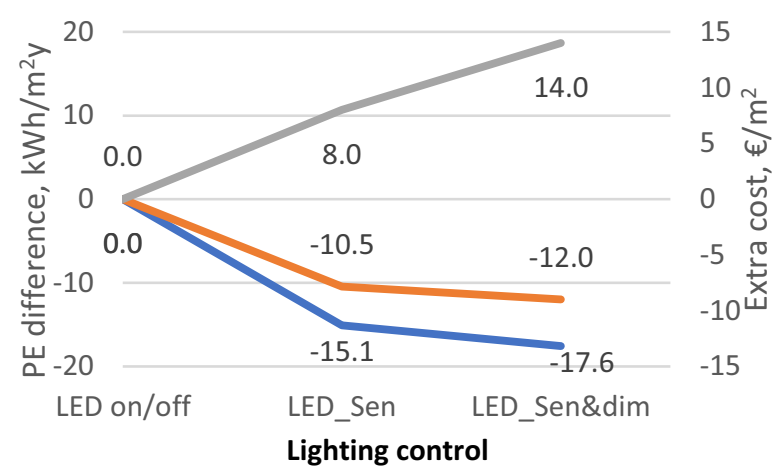

Figure 4. Lighting control measure primary energy (PE) change and extra investment cost compared to the base model

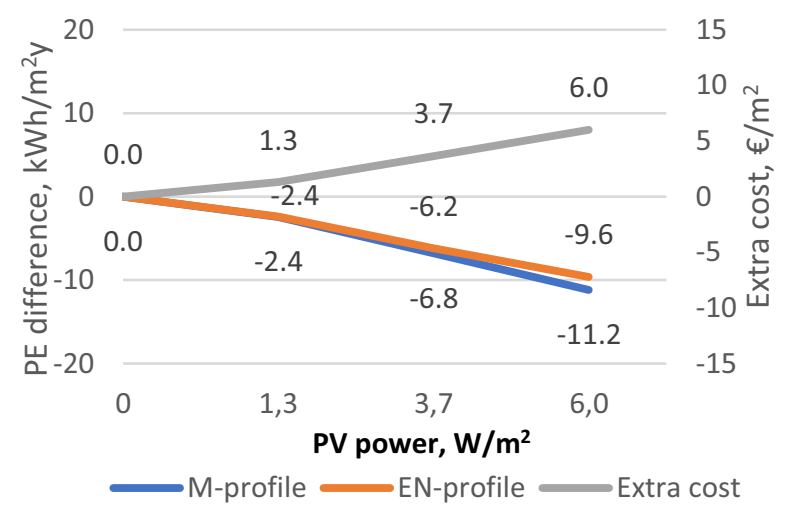

Figure 5. PV power measure primary energy (PE) change and extra investment cost compared to the base model

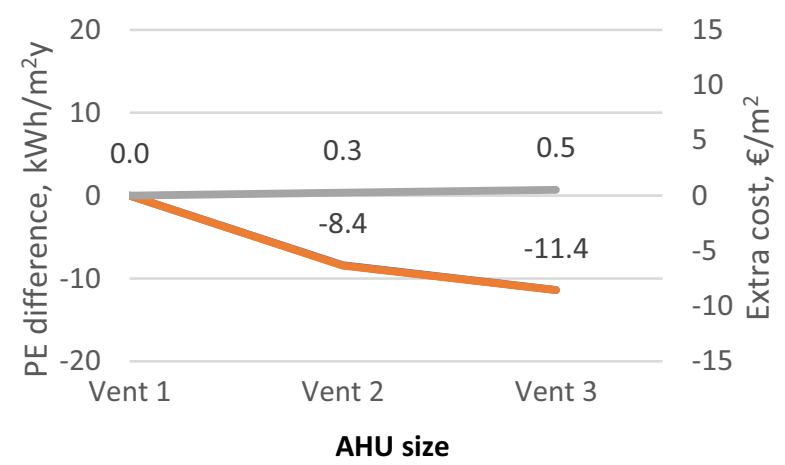

Figure 6. AHU size measure primary energy (PE) change and extra investment cost compared to the base model 


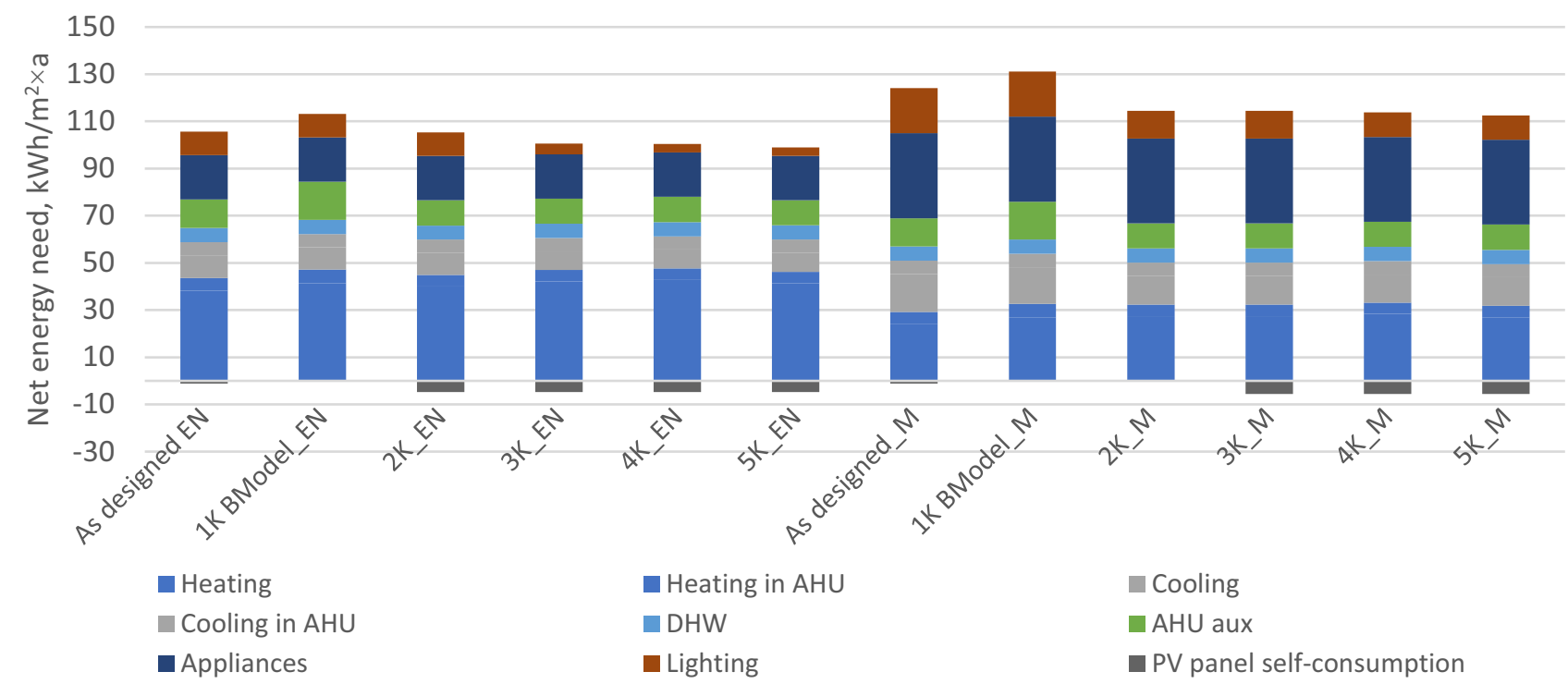

Figure 7. Net energy use of selected combinations of EN and measurement-based profile

\subsection{The cost-optimal solutions}

The cost-optimal solutions were combined with the best measures that had an investment cost per saved primary energy below $1 € / \mathrm{kWh}$ and the insulation thickness measures were excluded. Combination as lighting control with sensors and dimming had the investment cost around $3 € / \mathrm{kWh}$, which was aslo included, but Figure 9 shows that this was more expensive measure compared to others. Furthermore, if compare measures like lighting control with motion sensors and PV power $6 \mathrm{~W} / \mathrm{m}^{2}$, one can see in Figure 9 that there was a big difference in investment cost per saved PE for EN-profile compared to M-profile, where the difference was almost zero.

Pareto front (Figure 8) shape for combinations was similar for both profiles. The only exception is the combination $2 \mathrm{~K}$. Turns out that the input data did not influence the cost-optimal solutions.

EN-profile reduced the PE use of cost-optimal solutions about $20 \mathrm{kWh} / \mathrm{m}^{2} \times y$ compared to the designed building and increased the investment for $6,6 € / \mathrm{m}^{2}$. NPV over 20 -year period was $11 € / \mathrm{m}^{2}$ smaller than designed building. M-profile reduced PE use of cost-optimal solutions for $26 \mathrm{kWh} / \mathrm{m}^{2} \times \mathrm{y}$ and increased the investment for $6,6 € / \mathrm{m}^{2}$. NPV over 20 -year period was $15 € / \mathrm{m}^{2}$ smaller than for designed building.

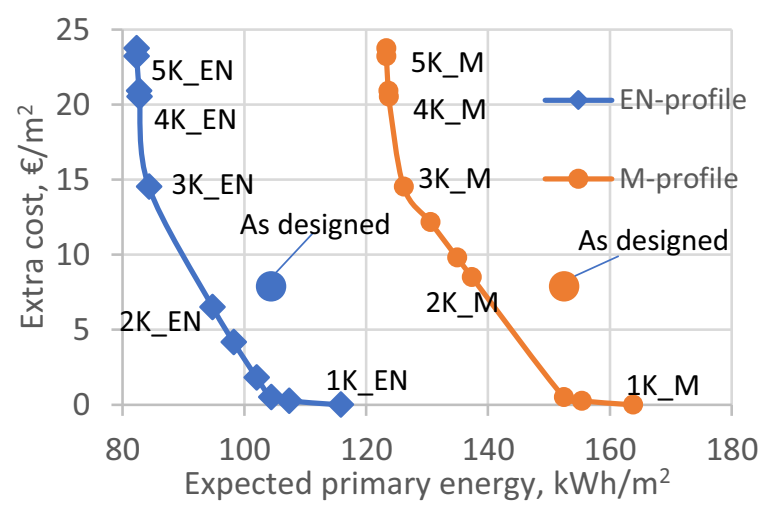

Figure 8. Pareto front for the cost-optimal solutions with EN16798-1 (EN) and measurement-based (M) profile

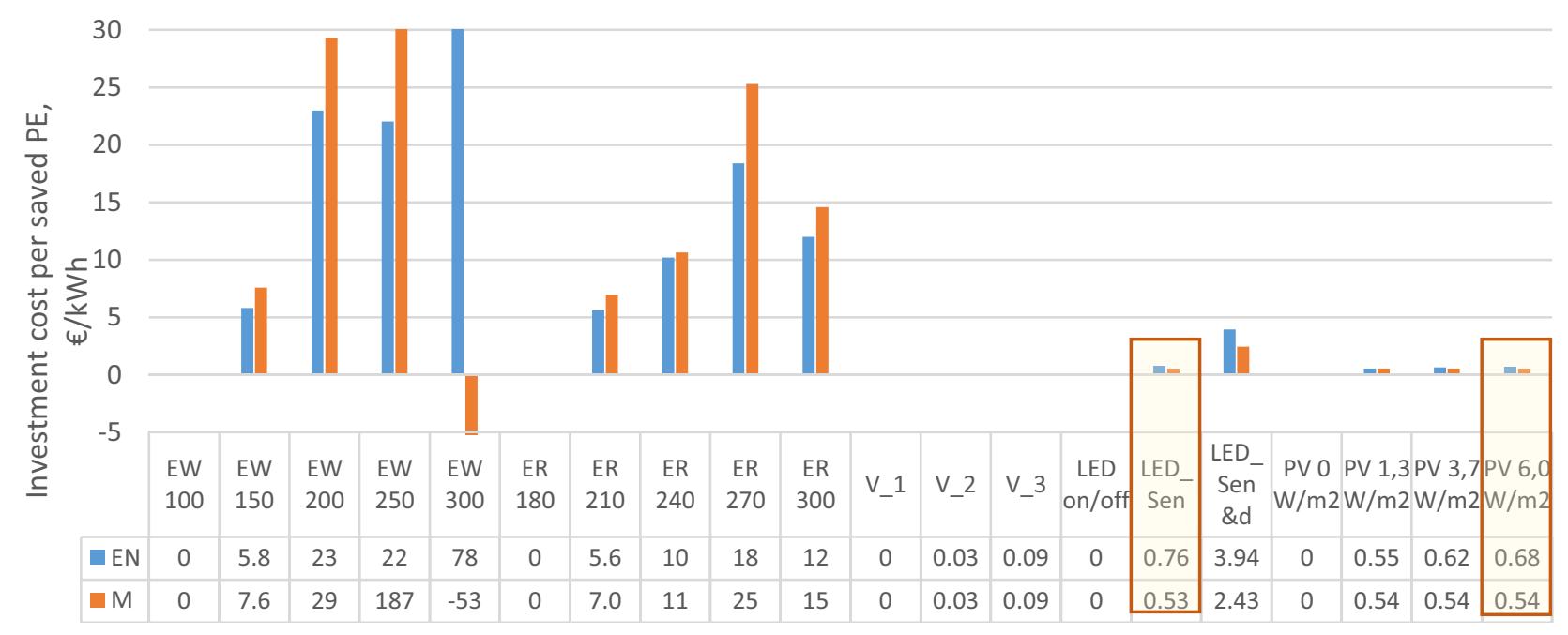

Figure 9. The investment cost of measures per saved primary energy, $€ / \mathrm{kWh}$ 


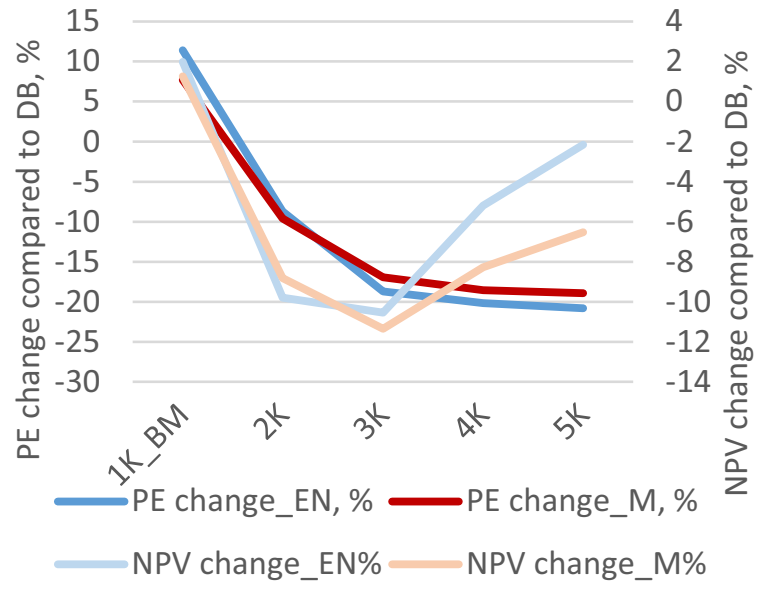

Figure 10. Primary energy and net present value change compared to the designed bld.

From Figure 10 and Figure 11 one can see that Mprofile behaves similarly to EN-profile. Combination $2 \mathrm{~K}$ was different because of dissimilar measures between profiles (look Table 4). The M-profile relative NPV change was higher for the same measures. The higher was the investment, the bigger was the difference in between profiles. The NPV change difference between profiles was twofold for combination $5 \mathrm{~K}$. PE relative change was similar for profiles. However, the change was bigger for EN-profile.

The combination with the smallest NPV was $3 \mathrm{~K}$ with bigger AHU, PV panels with power $6.0 \mathrm{~W} / \mathrm{m}^{2}$, and lighting with motion sensor control. The dimming will improve the energy efficiency, but the investment rises too much.

\section{Conclusion}

This study presents the impact of tenants' electricity use on cost-optimal solutions on the example of one office building with heated area $3822 \mathrm{~m}^{2}$. Cost-optimal solutions were identified with EN 16798-1:2019 input data and compared with solutions identified with the model derived from measurements in the real building. The variables were building envelope insulation thickness, air handling unit size and effectiveness, electrical lighting control principles, and PV system nominal power.

The investigation shows that the primary energy use for the measures calculated with M-profile was about $37-52 \mathrm{kWh} / \mathrm{m}^{2} \mathrm{y}$ higher than for the model with ENprofile. This was caused by increased lighting and appliances energy use. Greater difference of primary energy between profiles came from measures that reduced electricity use considerably.

The investigation over PV panel system shows that the higher was the nominal power, the higher was the exported energy (self-consumption was lower), but for the cases in this study, the self-consumption was for measurement-based profile $100 \%$ and for EN-profile $86-98 \%$. Concerning the cost-optimal solutions, the profiles behave similarly. Still, there was one difference with the second combination, where lighting on/off

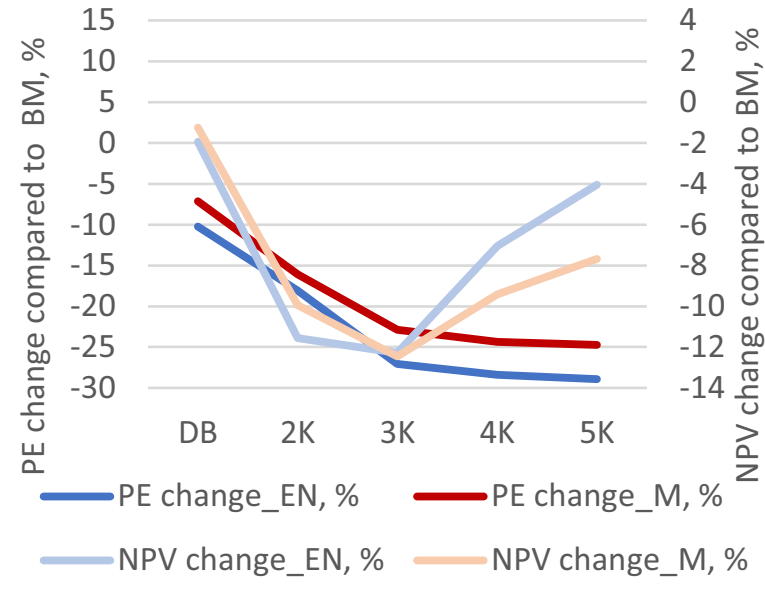

Figure 11. Primary energy and net present value change compared to the base model

control and $6.0 \mathrm{~W} / \mathrm{m}^{2} \mathrm{PV}$ panel power was preferred for EN-profile. However, lighting with motion sensor and without PV panel installation was preferred for Mprofile.

This study in the case of one office building shows that even if the profiles differ on energy use, still the cost-optimal solutions are the same. Therefore, in this case, it is recommended to use the standard profiles to keep the comparison with other buildings. However, this study has been done with measurement data from a building with extreme energy use that is unusual for a general office buildings. The results can not be generalized for other office buildings (at least not for administrative office buildings). Therefore, future studies should include measurement data from a reference buildings with normal energy use.

A future studies should add also the window size optimization and other primary heat sources (for example, district heat and natural gas) under investigation.

This study did not include the impact of changing the thickness of the insulation and the size of the AHU device on the value of the real estate.

Furthermore, the impact of cost-optimal solutions on heat pump power could be under investigation in future studies.

The authors are grateful for Mitt \& Perlebach OÜ especially for Martin Varvas and Madis Leps for giving good input for this study. Thanks to Vahur Maask and Hans Kristjan Aljas. This research was supported by the Estonian Centre of Excellence in Zero Energy and Resource Efficient Smart Buildings and Districts, ZEBE (grant 2014-2020.4.01.150016) funded by the European Regional Development Fund, by the European Commission through the H2020 project Finest Twins (grant No. 856602) and the Estonian Research Council grant (PSG409).

\section{References}

[1] E. G. Ordinance, "Minimum requirements for energy performance of buildings," 2019. 
[2] E. G. Ordiance, "Methodology for calculating the energy performance of buildings," 9 January 2013. [Online]. Available: https://www.riigiteataja.ee/en/eli/520102014002/c onsolide. [Accessed 1 February 2021].

[3] EU, "Directive 2010/31/EU of the European Parliament and of the Council of 19 May 2010 on the energy performance of buildings," 2010.

[4] EU, "Directive 2012/27/EU of the European Parliament and of the Council on energy efficiency," 2012.

[5] J. Kurnitski, T. Kalamees, A. Hamburg, K. Kuusk, T. M. Kull, J. Fadejev, M. Kiil and T. Tark, "Energy performance certificate correspondence to real energy use (Hoonete arvutuslike energiamärgiste vastavus tegelikule)," TalTech, 2016.

[6] A. Engels, "Master thesis on electricity use in two office building in Tallinn Ülemiste City (Elektritarbimise analüüs kahe büroohoone näitel Tallinnas Ülemiste Citys)," TalTech, 2019.

[7] H. K. Aljas, A. Ferrantelli, V. Maask and M. Thalfeldt, "Tenant-based measured Electricity Use in 4 large Office Buildings in Tallinn, Estonia," in Cold Climate HVAC \& Energy 2021 - E3S Web of Conferences, Tallinn, 2021.

[8] T. Kalamees and J. Kurnitski, "Estonian test reference year for energy calculations," Proceedings of the Estonian Academy of Sciences, pp. 40-58, 2006.

[9] J. Kurnitski, Saari, Arto, T. Kalamees, Vuolle, Mika, Niemelä, Jouko and Tark, Teet, "Cost optimal and nearly zero energy performance requirements for buildings in Estonia," Estonian Journal of Engineering, vol. 19, no. 3, pp. 183202, 2013. 


\section{Appendix 1}

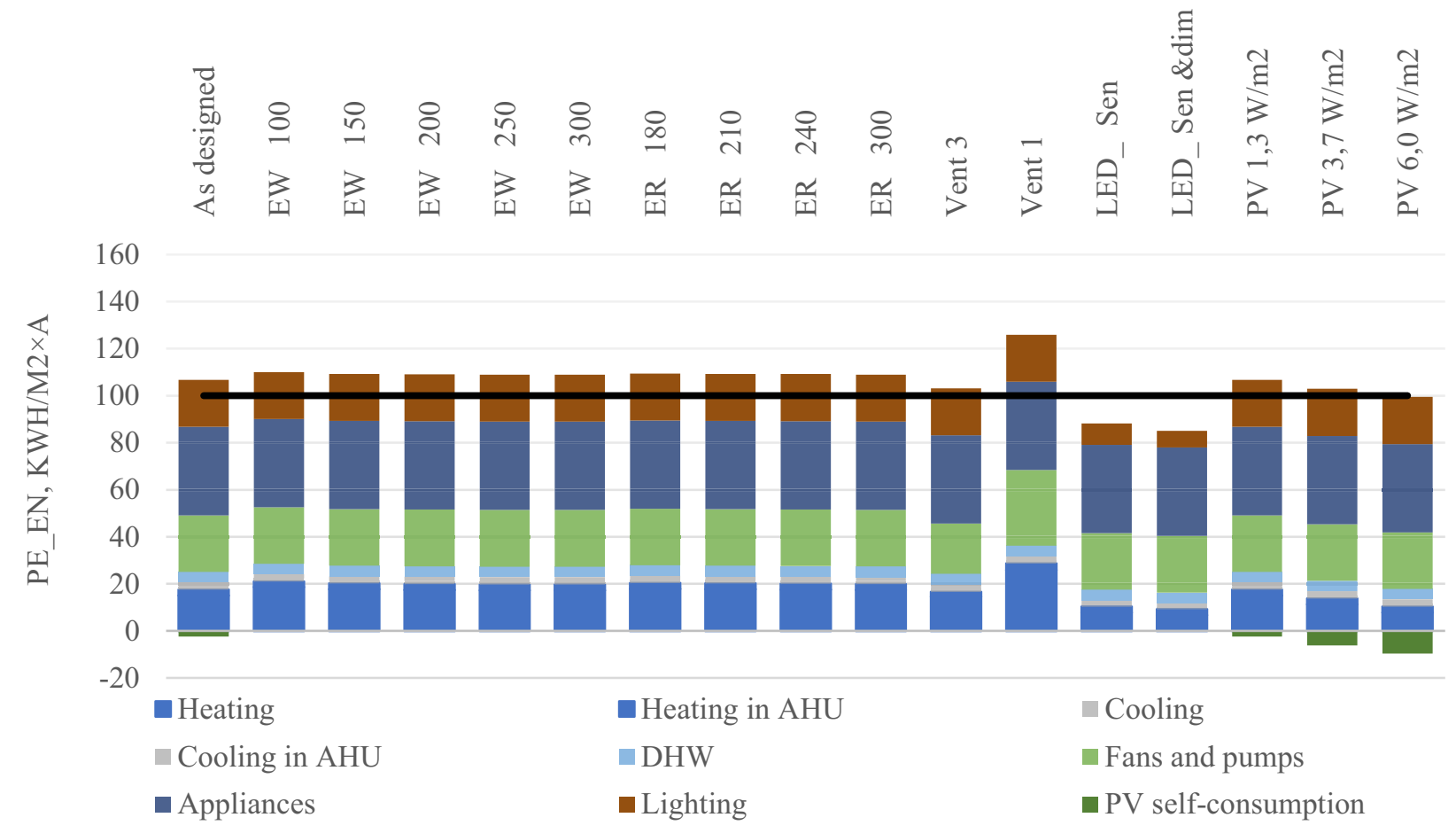

Figure 12. Primary energy (PE) use with EN16798-1 input data of all selected measures (black line is the requirement boundary)

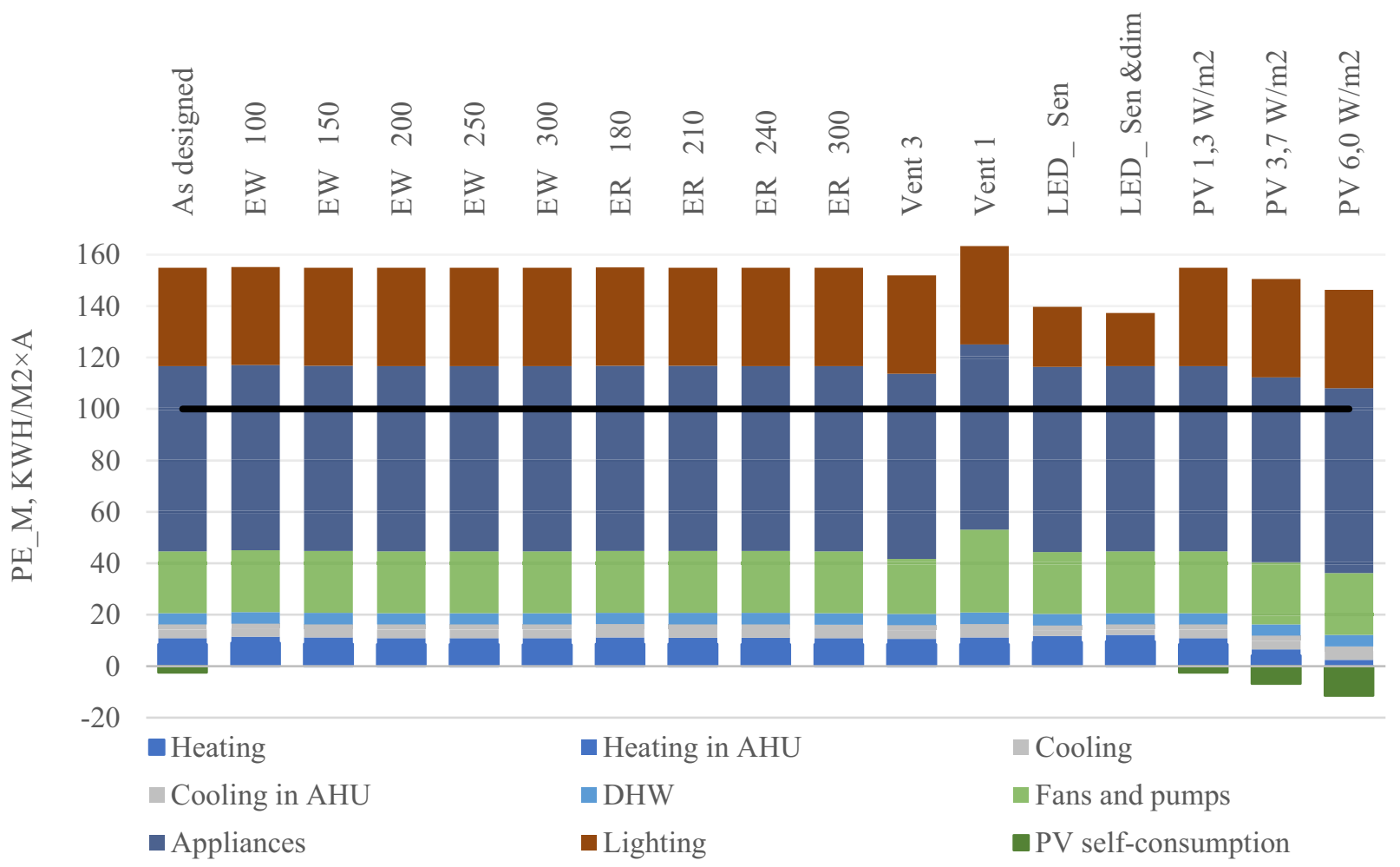

Figure 13. Primary energy (PE) use with measurement-based model input data of all selected measures (black line is the requirement boundary) 